\title{
Obtenção da Voz do Consumidor: estudo de caso em um Hotel Ecológico
}

\author{
Augusto de Toledo Cruz Junior \\ Mestre em Eng. de Produção da Escola Politécnica da USP \\ E-mail: seneng@uol.com.br \\ Marly Monteiro de Carvalho \\ Profa. Doutora do Depto. de Eng. de Produção da Escola Politécnica da USP \\ E-mail:marlymc@usp.br
}

\begin{abstract}
Resumo
Selecionar as métricas adequadas para compreender e monitorar a satisfação dos clientes é decisivo para que a empresa oriente suas ações e decisões de melhoria na busca do atendimento destas necessidades, em especial no setor de serviços, em que a retenção dos clientes é uma fonte de vantagem competitiva.

Neste artigo apresenta-se uma proposta de aferição da satisfação do cliente para o setor de serviços. A pesquisa foi desenvolvida através da abordagem metodológica de estudo de caso, realizado num Hotel Ecológico, no qual é introduzida uma classificação para as características de qualidade críticas, bem como o uso do AHP (Analytic Hierarchy Process] como ferramenta de priorização das métricas no modelo proposto. Neste trabalho, propõe-se um instrumento de obtenção da voz do consumidor e uma aplicação piloto.
\end{abstract}

Palavras-chave

Voz do consumidor, serviços, hotel, AHP.

\section{Obtaining the Voice of Customer: a case study in an Ecological Hotel}

\begin{abstract}
The selection of appropriate metrics to better understand the customer needs is critical. These customer needs should be the driver of company decisions in order to achieve a competitive advantage especially on service sector. This paper presents a customer satisfaction metric system to be used in the service sector. This research was developed through the case study methodology performed in an Ecological Hotel. A ranking of critical characteristics was obtained through the AHP method (Analytical Hierarchic Process]. This work is directed toward a proposal of a voice of customer tool and pilot application.
\end{abstract}

\section{Key words}

Voice of customer, services, hotel, AHP - Analytical Hierarchic Process. 


\section{INTRODUĈ̣̃O}

As grandes tendências internacionais de crescimento do setor de turismo chegaram tardiamente ao Brasil. No entanto, os gastos neste setor têm crescido nos últimos anos, principalmente no seguimento que explora o turismo ecológico.

Apesar dos sinais de crise do setor estarem se dissipando, a crise teve reflexos significativos nos modelos de gestão adotados, com profissionalização da administração, capacitação e treinamento do corpo de funcionários e focalização. Destaca-se, ainda, uma estratégia mais agressiva na captação de novos clientes e fidelização dos clientes retidos, aliada a maior preocupação com a qualidade dos serviços e com a satisfação do cliente. Esta abordagem mais voltada à compreensão das necessidades dos clientes demanda a adoção de técnicas mais elaboradas para a obtenção da voz do consumidor e pesquisas de satisfação.

Vários autores destacam a importância de compreender o cliente e suas necessidades como um aspecto decisivo para as organizações obterem vantagens competitivas sustentáveis, em especial no setor de serviços, cuja proximidade com cliente demanda um diálogo ativo, bem como exige o uso de métricas que permitam avaliar a discrepância entre expectativas e impressões na avaliação dos clientes (HAUSER; CLAUSING, 1988; CHASE; GARVIN, 1989; PARASURAMAN et al., 1990; HAMEL; PRAHALAD, 1991; BERRY; PARASURAMAN, 1992; HAUSER; KATZ, 1998; FISHER; SALIBA, 2000; PRAHALAD; RASMAWANY, 2000; CARVALHO, 2002). Contudo, Hauser; Katz (1998) alertam que o uso incorreto de métricas pode transformar a organização e não produzir o resultado esperado.

Neste artigo apresenta-se uma proposta de aferição da satisfação do cliente para o setor de serviços. A pesquisa foi desenvolvida através da abordagem metodológica de estudo de caso (YIN, 1991), realizado em um Hotel Ecológico, no qual é introduzida uma classificação para as características de qualidade críticas, bem como o uso do AHP - Analytic Hierarchy Process (SAATY, 1990) como ferramenta de priorização das métricas no modelo proposto. Neste trabalho discute-se nas seções iniciais o arcabouço teórico utilizado, em seguida apresenta-se o modelo e uma aplicação piloto.

\section{MÉTRICAS PARA OBTENC̣̃̃O DA VOZ DO CONSUMIDOR}

Para Hauser; Katz (1998), conforme sugere o título provocativo do artigo "Você é o que você mede", as métricas alimentam um processo de ação e reação, com conseqüências críticas para as organizações se não forem bem definidas. Segundo estes autores, as métricas, independentemente da forma como são utilizadas, afetam as ações e as decisões na organização, que por sua vez afetam os resultados obtidos.

Hauser; Katz (1998) defendem que boas métricas são difíceis e trabalhosas de serem implementadas, alertando para sete armadilhas que devem ser evitadas:

1. atraso nas recompensas, evitando atrelar metas e recompensas apenas de longo prazo;

2. uso de recompensas arriscadas, que afetem a escolha/ rejeição de projetos em função de métricas não claras que permitem a escolha pelo menor risco, comprometendo as probabilidades de resultados de longo prazo;

3. uso de métricas de difícil controle e correlação com as atividades do dia-a-dia;

4. perda dos objetivos de vista, de tal forma que as métricas distorçam os objetivos reais da organização, por não estarem alinhadas com as reais necessidades dos clientes e do negócio da empresa;

5. escolha de métricas que são precisamente incorretas, ou seja, métricas que são aferidas com grande precisão, mas que perdem o foco, pois não são claras para os gerentes e empregados;

6. todo o custo e o esforço na implementação, controle e busca de resultados esperados por um sistema de métricas não refletirem em valor adicionado a empregados e gerentes;

7. pensamento estreito, ou seja, deve ser um sistema de métricas de forma criativa, quebrando paradigmas.

Por outro lado, os autores recomendam sete passos para a obtenção de um bom sistema de métricas, conforme a seguir.

1. Começar escutando o cliente (voice of customer-VOC), de forma a determinar quais resultados devem ser buscados e, conseqüentemente, quais metas devem ser implementadas.

2. Entender o trabalho (voice of employee - VOE), ou seja, o que gera valor para o empregado além das bonificações financeiras, ponderar estes valores, e entender os processos de negócio e as atividades.

3. Entender as inter-relações entre as métricas, visando garantir sinergia no uso de diversas métricas, evitando metas conflitantes entre departamentos que atrapalhem na busca do resultado do todo, da organização.

4. Entender as ligações entre as diversas métricas, identificando as necessidades dos clientes, procurando entender como elas podem ser alcançadas através dos processos internos e estabelecer uma ligação entre estes processos e os resultados esperados.

5. Procurar testar as correlações entre métricas e resultados, 
obtendo informações de gerentes e empregados durante a sua implementação e utilizando-se de projetos pilotos, pesquisas e comunicação.

6. Envolver as pessoas que utilizarão e sofrerão as pressões do sistema de métricas na sua elaboração, garantindo que a participação traga legitimidade, comprometimento e melhor entendimento.

7. Procurar novos paradigmas, utilizar os passos de um a seis de forma criativa, não limitando a organização.

\section{Métricas utilizadas no setor de servicos}

De acordo com NBR ISO 8402:1994 (ASSOCIAÇÃO BRASILEIRA DE NORMAS TÉCNICAS, 1994, p.3), "Os serviços são resultados gerados por atividades na interface entre o fornecedor e o cliente e, pelas atividades internas do fornecedor, para atender às necessidades do cliente".

Embora alguns princípios básicos de gestão possam ser aplicados universalmente a operações tanto de manufatura quanto de serviços, estes têm algumas características únicas e específicas que devem ser levadas em consideração ao se desenvolver um sistema de métricas para serviços. De acordo com Albredcht; Bradford (1992), a qualidade de um produto é encarada de forma diferente da qualidade do serviço. senta duas dimensões para a qualidade de um serviço: técnica e funcional. A dimensão técnica está relacionada ao resultado que o cliente recebe em suas interações com a empresa prestadora de serviço. A dimensão funcional está relacionada à forma como os clientes recebem o serviço, durante os momentos da verdade.

Para medir a percepção do cliente a respeito da qualidade em serviços, Parasuraman et al. (1990) desenvolveram um instrumento chamado SERVQUAL, baseado nas dez dimensões apresentadas anteriormente. As análises estatísticas elaboradas em função do SERVQUAL permitiram identificar correlações entre as dez dimensões, o que resultou no agrupamento em cinco dimensões: garantia (derivada de competência, cortesia, credibilidade e segurança); empatia (fusão de acesso, comunicação e entendimento do cliente); tangibilidade; confiabilidade; presteza. Estes autores argumentam que para se ter uma alta qualidade nos serviços é preciso fazer um balanço entre as expectativas dos clientes e sua percepção, aproximando-as. Portanto, para aumentar a satisfação dos clientes a empresa prestadora de serviço deve estabelecer uma conexão entre a qualidade dos processos internos e as percepções de qualidade e satisfação dos clientes, envolvendo para tal um importante e complexo processo de translação (GUSTAFSSON; JOHNSON; 1997). Neste sentido a metodologia SERVQUAL pode ajudar a apontar quais são as principais discrepâncias (gaps) existentes na prestação do serviço ao avaliar e entender a percepção da qualidade do serviço do cliente. Berry; Parasuraman (1992) também destacam como fator primordial à identificação destas discrepâncias (gaps). Para os autores, o termo expectativa pode ser inter-

Várias técnicas de medição podem avaliar a qualidade de processos de negócios, produtos e serviços. Porém, nota-se a necessidade de se utilizar medidas subjetivas ou intrínsecas no sistema de métricas para serviços, sobretudo no que concerne à linha de frente (front office). Tais medidas enfocam a percepção e atitude, em vez de um critério mais objetivo e concreto, permitindo obter um entendimento abrangente da atitude dos clientes em relação a produtos e serviços. Pode-se citar como medidas subjetivas à satisfação, cortesia, confiança, prestabilidade, credibilidade, segurança, empatia, etc. (FISHER; SALIBA; 2000).

Parasuraman et al. (1990) afirmam que a qualidade dos serviços pode ser descrita com base em dez dimensões, a saber: tangibilidade, confiabilidade, presteza, competência, cortesia, credibilidade, segurança, acesso, comunicação e entendimento do cliente. Já Grönroos (1996) apre- pretado com dois sentidos diferentes: previsões - o que os consumidores acreditam que ocorrerá quando se defrontam com um serviço; desejos - o que eles esperam que aconteça.

\section{Obtendo a voz do consumidor}

Segundo Carvalho (2001), captar a "voz do consumidor" - VOC (voice of customer), ou seja, os atributos que influenciam a percepção do consumidor para a qualidade do produto/serviço, é uma tarefa de monitoramento contínuo, não só pela dinâmica natural de evolução desta percepção ao longo do tempo, mas também pela melhoria dos padrões de desempenho da concorrência que acabam por influenciar os níveis de desempenho demandados pelo consumidor.

Chase; Garvin (1989), em seu artigo intitulado "fábrica de serviços", destacam que as organizações têm que se 
habituar a trabalhar num sistema aberto, conhecendo profundamente as necessidades de seus clientes. Garvin (1993) salienta ainda que manter canais de comunicação com os consumidores invariavelmente estimula o aprendizado organizacional.

Não obstante, Prahalad; Rasmawany (2000) argumentam que não é fácil aproveitar as competências do consumidor, demandando da organização engajar seus clientes em um diálogo ativo, claro e constante, mobilizando comunidades de consumidores e administrando as diferenças entre eles, além de propiciar experiências personalizadas.

As empresas que conseguirem aproveitar o capital intelectual tanto da força de trabalho como dos clientes, convertendo-o em competências, terão maior chance de obter sucesso no cenário competitivo desenhado pela nova economia. Para tal, Prahalad; Rasmawany (2000) destacam que é preciso rever os sistemas tradicionais de gestão e as estruturas organizacionais.

Hamel; Prahalad (1991) alertam, no entanto, que as empresas devem conduzir os consumidores e não simplesmente segui-los. Estes autores diferenciam três tipos de empresas:

- aquelas que simplesmente perguntam ao consumidor o que ele quer, sendo eternas seguidoras;

- aquelas que tentam puxar o consumidor para onde elas desejam;

- aquelas que conduzem o consumidor para onde ele gostaria de ir antes mesmo de ele saber disso.

Segundo Carvalho (2002), existem várias formas de se obter a "voz do consumidor", podendo-se utilizar métodos direto ou indireto, ou ainda a combinação de ambos. Contudo, deve-se ter bastante cautela na escolha dos métodos, uma vez que se estará tentando obter necessidades explícitas e implícitas dos consumidores. Existem casos em que questões formuladas aos consumidores (método direto) não são adequadas, pois o consumidor "esquece" ou não consegue articular corretamente suas necessidades; nestes casos, Garvin (1993) sugere que eles sejam observados em ação (método indireto). As técnicas mais utilizadas para obtenção da VOC são as seguintes: entrevistas, grupos focais, simulação da situação de consumo além da pesquisa de mercado. Uma vez obtido um elenco de atributos relevantes para o consumidor, é importante proceder às medições e priorizações com vistas ao atendimento das necessidades dos clientes (GUSTAFSSON; JOHNSON, 1997).

Segundo Kano et al. (1984), a "voz do consumidor" pode ser dividida em itens básicos da qualidade; itens de desempenho; ou itens de encantamento do consumidor. Os itens básicos são considerados importantes para o cliente somente se não estão presentes no produto. Neste caso, diz-se que é a qualidade esperada ou "preço de admissão" ao mercado. É preciso observar que estes itens não são declarados pelo consumidor e estão geralmente ligados à confiabilidade do produto, como no exemplo do avião. Portanto, para obtê-los é necessário analisar as reclamações dos consumidores. Os itens de desempenho são requisitos declarados, de qualidade unidimensional, podendo ser obtidos por entrevistas ou outro tipo de pesquisa direta com o consumidor. Já os itens de encantamento têm importância exponencial na satisfação dos consumidores. Entretanto, tais itens não podem ser obtidos do consumidor, que ainda não está buscando estas características no produto. Para obter os itens de encantamento, o time de projeto deve acompanhar as inovações tecnológicas e observar o comportamento dos consumidores (CARVALHO, 2002).

\section{ASPECTOS METODOLÓGICOS}

Este artigo pretende analisar o processo de obtenção da VOC, buscando identificar os aspectos críticos para a construção e implementação de um sistema de métricas. Para este fim, optou-se pela abordagem de estudo de caso, que permitiria analisar em profundidade estes fatores (YIN, 1991).

O estudo de caso foi realizado em um Hotel Ecológico de capital nacional, com cerca de cinqüenta funcionários. Foram feitas entrevistas com diversos atores de diferentes níveis hierárquicos, da área de venda de pacotes e da gestão do hotel, que são dispersas geograficamente.

O modelo referencial de análise do caso pautou-se no arcabouço teórico apresentado. Para a construção do modelo piloto foi utilizado o diagrama de Afinidades ou KJ (SHIBA et al., 1997) como técnica de agrupamento do elenco de atributos e o AHP - Análise Hierárquica do Processo como ferramenta de priorização (SAATY, 1980).

\section{ESTUDO DE CASO}

Este trabalho foi desenvolvido em um conjunto hoteleiro ecológico situado em uma região de difícil acesso, mas conhecida e apreciada entre os freqüentadores deste tipo de turismo. Apesar de o Hotel Ecológico não pertencer a nenhum grande grupo hoteleiro e ser de origem nacional, é muito conceituado, tanto por turistas brasileiros, quanto por estrangeiros, principalmente americanos e europeus.

O hotel estudado situa-se em um local de preservação ecológica, que convive com um complexo pecuário, ambos com autorização de manejo dos órgãos ambientais, pois a natureza e a fauna estão em região de preservação. 
As principais atrações oferecidas pelo Hotel são passeios ao ar livre do tipo safári, para que os turistas possam admirar a natureza e a fauna abundante do local. Os passeios são realizados em veículos, cavalos, barcos, etc., com o acompanhamento de guias com formação universitária em biologia ou veterinária, e com especialização na área ambiental. Como muitos dos turistas são estrangeiros, os guias falam pelo menos o inglês.

O Hotel é responsável pelo translado até o local, pois a cidade mais próxima dista aproximadamente quarenta quilômetros de estrada de terra e a cidade onde há vôos regulares fica a cerca de 300 quilômetros. Os hóspedes são alojados em pousadas muito confortáveis, de maneira a atender as exigências dos turistas, em geral das classes média e alta. O hotel estudado oferece regime de pensão completa, com comida regional e internacional. A estadia média no hotel é de três dias.

A venda dos pacotes é realizada através de agências de viagens e/ou operadoras de viagens, tratando-se de uma vasta rede internacional de operadores e agentes de viagens que trabalham em cadeia. Por exemplo, é possível imaginar que um turista suíço tenha inicialmente adquirido o seu pacote na própria Suíça, cuja operadora tenha comprado de uma operadora portuguesa especializada em pacotes brasileiros, que tenha adquirido de um receptivo (operadora que lida principalmente com turistas estrangeiros) no Rio de Janeiro, que por fim tenha comprado do setor de reservas do Hotel Ecológico.

$\mathrm{O}$ setor de reservas se situa a $1.200 \mathrm{~km}$ do Hotel Ecológico, numa grande capital, próximo das agências e operadoras de turismo. Neste local funciona a direção do empreendimento, bem como a equipe de marketing para promover os produtos, mais uma equipe que processa as reservas e realiza a logística para o deslocamento dos turistas, e por fim a cobrança.

\section{Análise crítica do sistema de obtenção da voz do consumidor}

O Hotel Ecológico utiliza um questionário para avaliação dos serviços, que é entregue ao hóspede durante o jantar anterior à sua saída, pelo guia que o acompanha durante sua estadia. Esse questionário, conhecido por "Jogo de Faces" - pelo fato de as alternativas entre excelente, bom e ruim serem representadas por ícones de faces, não permite considerar a importância relativa entre as diversas questões, ou seja, o cliente não identifica os itens prioritários.

Todos os questionários preenchidos pelos hóspedes são analisados pelos responsáveis dos diversos setores do Hotel Ecológico e, em seguida, são enviados para a equipe de marketing, que calcula os indicadores para a direção do empreendimento. São realizadas reuniões regulares com os responsáveis dos setores para decisões e ações com base nos resultados da pesquisa, além do acompanhamento e verificação dos resultados das ações implementadas.

Analisando o sistema do Hotel sob a perspectiva de Hauser; Katz (1998), várias "armadilhas" puderam ser identificadas. A alta administração do hotel estudado estava preocupada com a dificuldade de tratar as informações obtidas por este questionário aplicado aos hóspedes, pois o julgava bastante extenso, o que poderia ser enquadrado como armadilhas 3 e 5. Além disto, o instrumento está focado basicamente na avaliação do desempenho do Hotel na prestação do serviço, sem uma preocupação em identificar o que realmente agrega valor, enquadrando-se nas armadilhas 4 e 6 . Finalmente, o sistema de métricas não tinha um vínculo específico com um sistema de recompensas para gerentes e empregados.

Neste contexto, identificou-se a necessidade de elaborar novo sistema de obtenção e tratamento da voz do consumidor que se pautasse nos sete passos para a obtenção de um bom sistema de métricas segundo Hauser; Katz (1998). Em especial, buscou-se envolver todos os interessados no sistema de medição, o que permitiria entender os processos de negócio e as atividades.

O modelo de avaliação proposto foi desenvolvido nas seguintes etapas:

- Análise crítica dos temas e questões aborda-

O Hotel Ecológico trabalha com três estações anuais: alta, média e baixa. As datas das estações, preços e demais condições necessitam ser informados aos agentes e operadores com um ano e meio de antecedência, principalmente para que possam ser inseridos nos catálogos estrangeiros. A contratação de recursos adicionais do hotel inicia na média estação e atinge o seu pico durante a alta estação. dos no questionário aplicado pelo Hotel Ecológico, com participação de todos os interessados (stakeholders).

- Benchmarking com os instrumentos de pesquisa utilizados por outros hotéis, escolhendo-se uma rede de resorts internacionais, com unidades em locais paradisíacos do Brasil.

- Definição e agrupamento dos temas críticos para análise da satisfação dos clientes, utilizando a ferramenta diagra- 
ma de afinidades, elaborada por especialistas do Hotel Ecológico, obtendo-se as principais classes e as interrelações entre elas.

- Com base no AHP - Método da Análise Hierárquica (SAATY, 1980) foi definida a classificação de prioridade das classes, definidas na etapa anterior, de forma a obter as características críticas para o cliente.

- Com base nas definições de prioridade foi desenvolvido um instrumento de obtenção da voz do consumidor e feita a aplicação piloto.

\section{Definição dos critérios para avaliação da voz do consumidor}

Segundo Shiba et al. (1997), as sete novas ferramentas, desenvolvidas pela JUSE (Japanese Union of Scientists and Engineers), têm por objetivo o tratamento e análise de dados verbais levantados junto a fontes internas e externas à empresa, que permitem completar planos de ação ou conduzir para novas idéias. O autor destaca que o tratamento das informações verbais tornase difícil devido às imprecisões e, em certos casos, à sua ambigüidade. As sete novas ferramentas do planejamento da qualidade são: diagrama de afinidades; diagrama de relações; diagrama matricial; diagrama de árvore; diagrama PDP; diagrama de setas; análise matricial de dados.

Neste trabalho utilizou-se o diagrama de afinidades, também denominado diagrama KJ em homenagem ao seu idealizador Prof. J. Kawakita. Este diagrama agrupa as informações verbais em classes homogêneas, com base nas suas afinidades. O objetivo do diagrama de afinidades é facilitar a obtenção de novas informações a partir daquelas disponíveis, especialmente se forem desconexas e não quantificáveis. Com a adoção desta ferramenta é possível a concepção de novas idéias, bem como a identificação das prioridades lógicas e a compreensão e estruturação de problemas poucos estruturados.

A utilização deste diagrama pode ser tanto individual como em grupo. Na utilização em grupo é necessário

Tabela 1: Passos para a construção do diagrama de afinidades.

\begin{tabular}{|c|c|}
\hline PASSO & PROCEDIMENTO \\
\hline A & Determine o tema ou projeto. \\
\hline $\mathrm{B}$ & $\begin{array}{l}\text { Levante dados e fatos referentes ao problema e também todas as opiniões e idéias criativas que } \\
\text { consiga coletar. }\end{array}$ \\
\hline C & $\begin{array}{l}\text { Escreva as expressões verbais identificadas no passo B em cartões chamados "cartões de dados" } \\
\text { (data card), seguindo o critério: uma informação - um cartão. }\end{array}$ \\
\hline $\mathrm{D}$ & $\begin{array}{l}\text { Espalhe os cartões em uma superfície plana, lendo com atenção duas ou três vezes cada cartão até } \\
\text { ter condições de reagrupá-los de acordo com as suas afinidades. }\end{array}$ \\
\hline $\mathrm{E}$ & $\begin{array}{l}\text { Para cada grupo de cartões afins prepare um novo cartão, contendo uma expressão verbal que } \\
\text { represente exatamente os conceitos de partida, evitando termos abstratos. Chame este novo cartão } \\
\text { de "cartão de afinidade" (affinity card). }\end{array}$ \\
\hline $\mathrm{F}$ & $\begin{array}{l}\text { Posicione o cartão de afinidade no topo do respectivo grupo de cartões afins e disponha-o entre os } \\
\text { outros cartões. }\end{array}$ \\
\hline G & $\begin{array}{l}\text { Repita os procedimentos de D a F, até conseguir reordenar todos os cartões afins em não mais de } 5 \\
\text { grupos. Alguns cartões de dados podem ficar isolados por causa das suas expressões específicas. }\end{array}$ \\
\hline $\mathrm{H}$ & $\begin{array}{l}\text { Para temas especialmente complexos, pode ser necessário neste momento realizar um segundo nível de } \\
\text { agrupamento, ou seja, reagrupar os cartões de afinidades identificados no passo G e dar um novo título. }\end{array}$ \\
\hline 1 & $\begin{array}{l}\text { Disponha os grupos de cartões em uma folha branca, lembrando que as suas posições relativas } \\
\text { dependem das inter-relações entre eles. }\end{array}$ \\
\hline J & $\begin{array}{l}\text { Examine o diagrama para avaliar a necessidade de eventuais integrações laparecimento de dados } \\
\text { gerados a partir do processo inverso } \rightarrow \text { do geral ao particular]. }\end{array}$ \\
\hline K & Cole todos os cartões na folha, conforme a disposição do item I. \\
\hline $\mathrm{L}$ & Indique as inter-relações e complete o diagrama escrevendo o título escolhido. \\
\hline M & Identifique os cartões e os grupos mais importantes. \\
\hline
\end{tabular}

Fonte: Adaptado de Shiba et al. (1997). 
eleger um líder com a responsabilidade de conduzir as reuniões e verificar se todos os participantes entenderam corretamente as informações coletadas. Os passos para a elaboração deste diagrama são apresentados na Tabela 1.

Com base no diagrama de afinidades, foi feito o agrupamento dos temas mais relevantes à análise das expectativas do cliente, utilizando como ponto de partida dois questionários, um utilizado pelo Hotel Ecológico estudado e o outro utilizado pelo Resort.

A dinâmica para elaboração do diagrama foi preparada pelos especialistas da equipe de marketing do Hotel (quatro pessoas) juntamente com o pesquisador. Para dar início ao processo, diversas questões dos questionários foram transformadas em cartões de dados. Os cartões de dados foram então apresentados aos especialistas do Hotel Ecológico que têm contato direto com os hóspedes (vinte pessoas), principalmente os guias, que têm o contato mais próximo com os hóspedes, e os responsáveis dos setores, que também interagem diretamente com os hóspedes, geralmente durante as refeições, visando ouvir pessoalmente seus depoimentos quanto ao atendimento e prestar esclarecimentos. A Figura 1 apresenta o resultado da aplicação do diagrama de afinidades. Cabe ressaltar que, apesar do procedimento sugerir que os cartões de afinidades sejam no máximo cinco, o trabalho desenvolvido no Hotel Ecológico não permitiu a redução abaixo de seis cartões de afinidades.

\section{Obtenção das prioridades entre os critérios}

O AHP (Analytical Hierarchic Process) é um método de apoio à decisão criado por Saaty na década de 1970, que permite incorporar tanto fatores qualitativos, quanto quantitativos, no processo de tomada de decisão.

Este método tem sido empregado para situações de definição de prioridades, avaliação de custos e benefícios, alocação de recursos, mensuração de desempenho, avaliação ou pesquisa de mercado, determinação de requisitos, decisões estratégicas, etc. (MORITA et al., 1999).

Segundo Laurindo et al. (2002), o modelo usa julgamentos comparativos de pares de fatores, estudando sua consistência e sua validade, de forma a não deixar de levar em consideração a ambigüidade decorrente da associação de números a julgamentos.

Segundo Carvalho (1997), apesar do amplo e crescente espectro de aplicações do AHP, existem algumas restrições quanto ao uso deste método, que podem ser aprofundadas nos trabalhos de Dyer (1990a;1990b) e Saaty (1990). Um destes problemas apontados no AHP é a quantidade de comparações paritárias necessárias que cresce muito rapidamente com o tamanho da matriz destas comparações. Existem técnicas que permitem reduzir este número de comparações paritárias. Dentre as críticas ao AHP, a reversão de ordem (a alteração das alternativas dominantes em função da inclusão ou exclusão de alternativas irrelevantes) tem sido a mais citada e polêmica (MORITA et al., 1999).

No AHP o problema de tomada de decisão é estruturado com base em três princípios: da estruturação das hierarquias, do estabelecimento de prioridades e da consistência lógica.

Talvez a tarefa mais criativa no modelo AHP seja a determinação dos fatores que comporão a hierarquia. $\mathrm{O}$ formato simples usado para estruturar um problema de decisão de forma hierarquizada em vários níveis, compreendendo um objetivo no topo, critérios que podem ser desdobrados em subcritérios nas camadas intermediárias, e alternativas na base. Portanto, uma hierarquia é uma estrutura na qual a influência é distribuída do topo para a base. Os elementos de um problema de decisão são colocados em níveis, dependendo do controle e influência que eles exercem nos níveis mais baixos. O propósito da estrutura hierárquica é facilitar o processo de definição de prioridades, permitindo julgar a importância dos elementos em dado nível com relação a alguns ou todos os elementos do nível adjacente acima. Desta forma, o uso do AHP permite entender as inter-relações, o que ajudaria na construção de um bom sistema de métricas segundo o passo 3 de Hauser; Katz (1998).

Para que a modelagem seja bem-feita, na construção das hierarquias devem ser incluídos todos os detalhes relevantes para a representação do problema, o mais próximo do real possível, considerando o ambiente que envolve o problema e envolvendo todos os tomadores de decisão. Caso haja um aumento das informações disponíveis ou mudança ambiental significativa, pode-se tornar necessário reestruturar a árvore hierárquica para conter os novos elementos. Com este objetivo, é útil que no momento da análise a atenção seja deslocada gradualmente em direção aos níveis de maior detalhe (top-down) ou de menor detalhe (bottom-up).

O método identifica as preferências através da comparação par-a-par dos critérios e alternativas. A escala fundamental usada nos julgamentos verbais é composta de cinco operadores lingüísticos - igual, moderadamente mais, fortemente mais, muito fortemente mais, extremamente mais - cujos correspondentes julgamentos numéricos são 1, 3, 5, 7, 9 e compromissos, 2, 4, 6, 8, entre esses julgamentos. Além disto, o método estabelece os pesos através do cálculo das prioridades como autovetor, o que permite ao tomador de decisões medir o grau de consistência do resultado obtido.

Um problema básico de fazer escolhas é que as decisões são caracterizadas por critérios múltiplos: ambigüi- 
Figura 1: Afinidades das questões de avaliação e inter-relações das afinidades
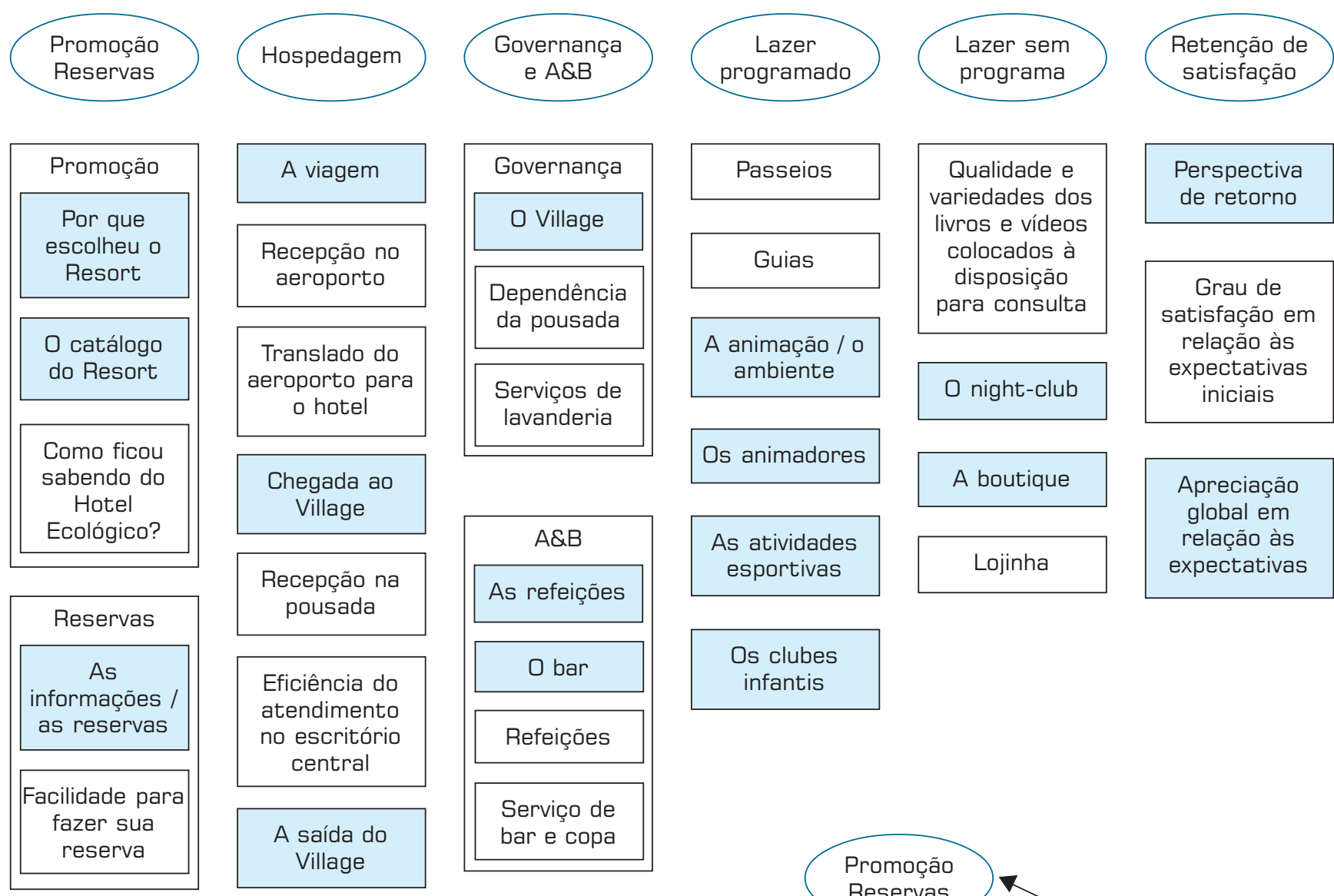

O night-club

Perspectiva de retorno
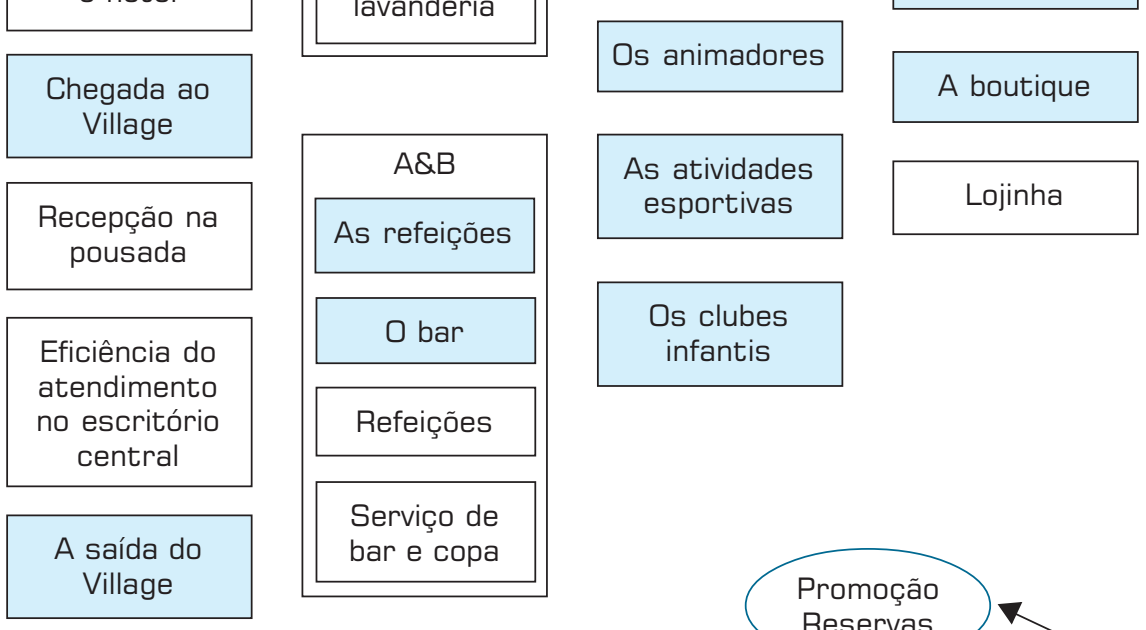

Grau de satisfação em relação às expectativas iniciais

Apreciação
global em
relação às
expectativas

\section{Os clubes infantis}

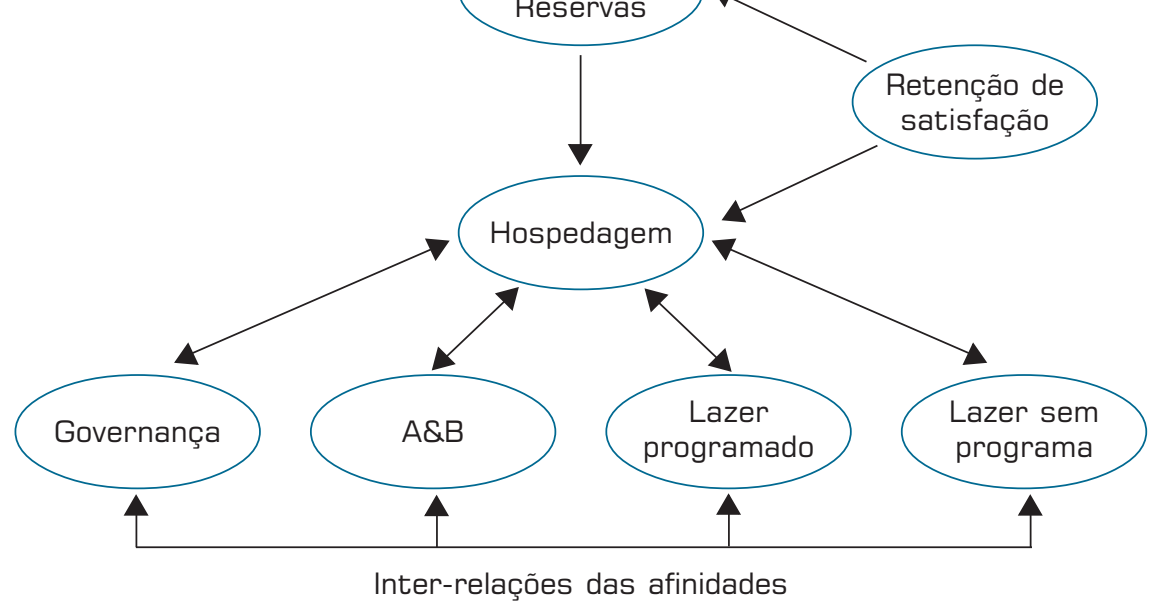

Afinidades das questões de avaliação

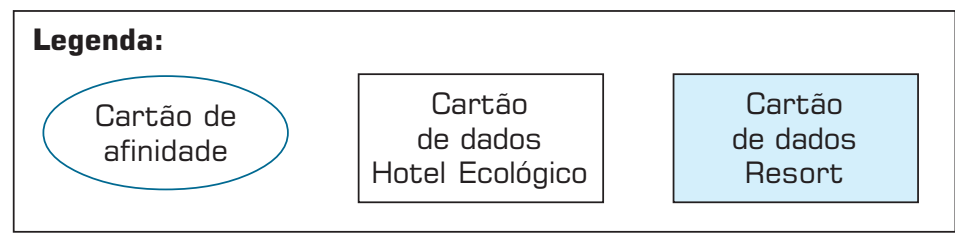


dade, risco, conflito de interesses, informações qualitativas e quantitativas. O AHP é uma abordagem que permite ao tomador de decisão lidar tanto com o racional quanto com o intuitivo, quando está selecionando o melhor número de alternativas desenvolvidas com vários critérios. Observa-se, no entanto, que podem ocorrer inconsistências nos julgamentos e é muito importante monitorar este problema durante todo o processo.

O Diagrama de Afinidades foi base para a construção do método AHP. Para este trabalho foi elaborada uma hierarquia em dois níveis, cujo primeiro nível - objetivo é satisfazer o cliente, seguido pelos seis critérios obtidos com a utilização do diagrama de afinidades. O julgamento par-a-par dos critérios foi efetuado por especialistas do Hotel Ecológico da equipe de marketing, pelos responsáveis pelos setores de A\&B (refeições e bar), Governança, Hospedagem e Lazer, além da direção do Hotel Ecológico, totalizando 10 pessoas. O trabalho foi conduzido pelo pesquisador utilizando o software Expert Choice e, durante algumas horas, foram feitas discussões e julgamentos dos critérios até que o nível desejado de consistência fosse obtido, conforme resultado ilustrado na Figura 2.
O critério julgado mais relevante pelos especialistas foi Promoção \& Reservas $(0,307)$, seguido de perto por Retenção de satisfação $(0,299)$, num patamar inferior de importância estão os critérios Lazer com programa $(0,166)$ e Hospedagem $(0,138)$ e, finalmente, menos importantes são Governança e A\&B $(0,064)$ e Lazer sem programa $(0,026)$.

\section{Interpretação dos resultados}

Em função do acompanhamento do julgamento dos especialistas, foi possível interpretar os principais motivos que levaram aos resultados de classificação apresentados anteriormente. Durante as discussões empreendidas durante o processo, foi possível destacar os seguintes:

- em função das negociações serem feitas através de várias agências espalhadas pelo mundo de maneira encadeada, considerou-se Promoção e Reservas primordial para fornecimento de informações adequadas sobre o local e as instalações, para evitar que o hóspede, principalmente do exterior, fique desapontado;

- a Retenção da satisfação reflete o atendimento das expectativas do contrato feito a distância;

Figura 2: Classificação dos critérios (resultados do software Expert Choice).

\title{
Importância da opinião dos hóspedes
}

\author{
Synthesis of Leaf Nodes with respect to GOAL \\ Ideal Mode \\ OVERALL INCONSISTENCY INDEX $=0,06$
}

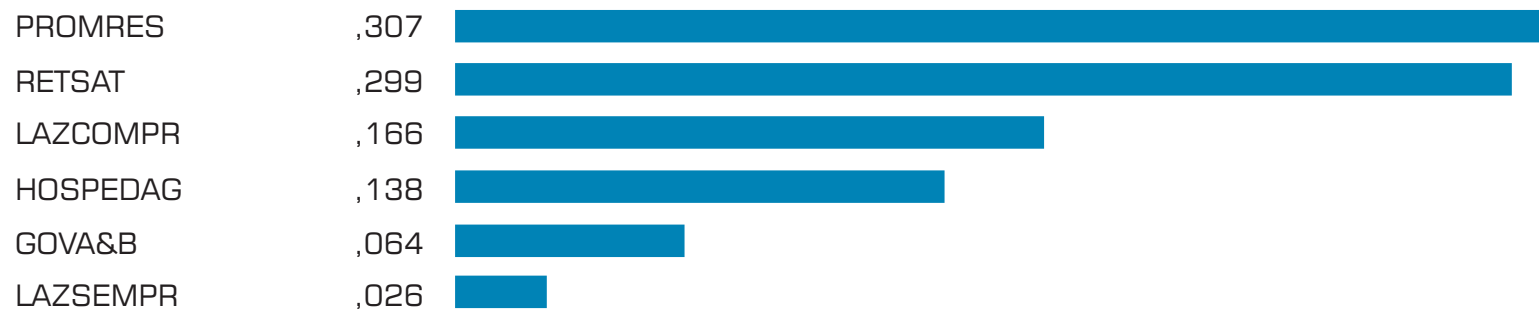

\begin{tabular}{|l|l|}
\hline \multicolumn{1}{|c|}{ Abbreviation } & \multicolumn{1}{c|}{ Definition } \\
PROMRES & Atividades de promoção e reservas \\
RETSAT & Retenção da satisfação \\
LAZCOMPR & Atividades de Lazer com Programa \\
HOSPEDAG & Atividades da Hospedagem \\
GOVA\&B & Atividades da Governança e A\&B \\
LAZSEMPR & Atividades de Lazer sem Programa \\
\hline
\end{tabular}


- o Lazer com programa, ou seja, passeios organizados e com educação ambiental, é o principal desejo dos hóspedes;

- a Hospedagem controla todas as necessidades particulares dos hóspedes e é o contato formal com o Hotel, a linha de frente (front office);

- a Governança e $\boldsymbol{O} \boldsymbol{A} \& \boldsymbol{B}$ não chamam tanto a atenção, pois aparecem apenas quando não estão sendo executados a contento, ou seja, geram insatisfação, representam a retaguarda (back room);

- o Lazer sem programa (piscina, sala de jogos, etc.) só é praticado nos momentos de folga, que são poucos, pois a rotina inclui diversos passeios em trilha.

A continuidade dessa aplicação piloto seria conduzir procedimento semelhante com um grupo de clientes fiéis de forma a confrontar estes resultados.

\section{Elaboração do novo instrumento de pesquisa de satisfação}

Com base nos resultados obtidos com a utilização do AHP, foi desenvolvido o novo instrumento de coleta de informações com base nas prioridades, bem como um sistema para medição das respostas dos hóspedes. Este sistema ajudaria o monitoramento dos níveis de satisfação dos hóspedes do Hotel Ecológico em função dos resultados. Além disso, como as classes estavam atreladas aos processos internos do Hotel, percebeu-se que seria também possível monitorar o desempenho dos setores individualmente, com base na voz dos hóspedes, o que auxiliaria na gestão dos próprios setores.

\section{O questionário e a sua medição}

Em função dos resultados obtidos parecerem aderentes com as opiniões dos especialistas do Hotel Ecológico, em um primeiro momento foi elaborado um novo questionário orientando-se pela classificação dos critérios de julgamento (ver Figura 2). Assim sendo, as quantidades de questões procuraram obedecer aproximadamente aos percentuais da importância obtido no AHP. A Tabela 2 apresenta a distribuição das questões por setor.
Num segundo momento, as questões por critério foram aperfeiçoadas por especialistas de marketing, que também consideraram necessário distribuí-las por 10 temas de fácil entendimento para o hóspede, os quais nem sempre coincidem com a denominação dos seis critérios de julgamento. Desta maneira, algumas questões colocadas sob um certo tema, como por exemplo "As refeições e o bar", que daria a impressão inicial de referir-se somente aos serviços do critério $\boldsymbol{A} \boldsymbol{\&} \boldsymbol{B}$, nem sempre são apenas as questões deste critério, podendo haver também, por exemplo, questões do critério Retenção da satisfação. Numa outra situação, um tema denominado "O seu apartamento" poderia ser associado apenas ao critério Governança, que junto com o $\boldsymbol{A} \boldsymbol{\&} \boldsymbol{B}$ deveria ter três questões dentre as 43 (ver Tabela 2). No entanto, sob esse tema existem quatro questões, seguindo o mesmo raciocínio anterior, ou seja, de inserir sob uma linguagem adequada ao hóspede também as questões de outros critérios, que são mais fáceis de serem percebidas sob um terminologia mais ilustrativa, mas mantendo as quantidades de questões por critério de julgamento da Tabela 2 .

De maneira a transformar a pesquisa meramente qualitativa em quantitativa, visando utilizar estatisticamente a voz do hóspede, as respostas das questões foram graduadas tanto qualitativamente (Baixa, Satisfatória e Alta) para interpretação semântica do hóspede, quanto quantitativamente, através de uma escala de Likert (PEREIRA, 1999) de 5 pontos (neste caso de 0 a 4), para uma interpretação aritmética da graduação proposta. A escala de Likert possui um ponto médio (neste caso 3) "para registro de manifestação de situação intermediária, de indiferença ou de nulidade" (PEREIRA, 1999, p.65), no qual fica marcado o local da oposição semântica, implícita nesta escala devido à presença desse ponto médio. Conforme lembra Pereira (1999, p.65), “o sucesso da escala de Likert deve residir no fato de que ela tem a sensibilidade de recuperar conceitos aristotélicos da manifestação de qualidades: reconhece a oposição entre contrários; reconhece gradiente; e reconhece situação intermediária". Além disso, possui uma boa relação entre

Tabela 2: Quantidade de questões por critério de julgamento.

\section{CRITÉRIO DE JULGAMENTO}

\begin{tabular}{|l|l|}
\hline Promoção e Reservas & \\
\hline Retenção da satisfação & \\
\hline Lazer com programa & \\
\hline Hospedagem & \\
\hline Governança e A\&B & \\
\hline Lazer sem programa & \\
\hline
\end{tabular}

\section{PERGENTUAL DO TOTAL}

\begin{tabular}{|c|c|}
\hline QUESTOES & PERGENTUAL DO TOTAL \\
\hline 13 & $30,2 \%$ \\
\hline 13 & $30,2 \%$ \\
\hline 7 & $16,3 \%$ \\
\hline 6 & $14,0 \%$ \\
\hline 1 & $6,98 \%$ \\
\hline
\end{tabular}

Nota: Total de 43 questões do questionário. 
precisão e acurácia, pois uma escala de mais pontos pode trazer um refinamento da precisão, mas por outro lado implica na perda da acurácia, já que o hóspede dificilmente percebe diferenças entre alguns pontos. Por outro lado, uma escala com menos pontos perde a precisão, pois faltam alternativas intermediárias para se posicionar adequadamente.

Na prática, a apresentação do local para resposta de cada questão (ver Figura 3) procura levar o hóspede a perceber:

- sob a palavra Alta somente a nota 4;

- sob a palavra Satisfatória as notas 1, 2 e 3, levando-o a escolher a nota 2 quando quer se mostrar neutro na questão, ou as notas 1 ou 3 quando demonstra alguma tendência para Baixa ou Alta, mas não deseja pontuar nelas;

- sob a palavra Baixa somente a nota 0 (zero).

De maneira a garantir um bom nível de resposta aos questionários, logo na chegada o hóspede é alertado que a entrega do questionário preenchido adequadamente dá o direito a receber brindes da loja do Hotel Ecológico, além de participar de sorteios anuais de novos brindes, que serão entregues no endereço preenchido no próprio questionário. Este último detalhe colabora para que o hóspede preencha corretamente visando ser localizado, além de possibilitar que o Hotel Ecológico possa acessálo futuramente, para outras promoções, sem precisar recorrer às agências e/ou operadoras intermediárias.

As médias dos pontos levantadas através dos inúmeros questionários permitem analisar tanto as tendências nos níveis de satisfação, como alertar para situações pontuais de satisfação ou insatisfação muito discrepantes da tendência. Além disso, permitem fazer agrupamento dos resultados das questões pelos critérios de julgamento, ou por setores do Hotel. Em função das quantidades diferentes de questões por critério de julgamento (ver Tabela 2) as médias acabam resultando ponderadas pelo número de questões em um certo critério em cada agrupamento. Dependendo do valor da média obtida, o Hotel Ecológico passou a classificar a satisfação do consumidor de acordo com os níveis de serviço, conforme a Tabela 3.

O mínimo aceitável para a direção do Hotel Ecológico é a situação "Regular", mas que não deve ser mantida. Nesse caso, são exigidas ações para melhorias. As situações denominadas "Ruim" e "Péssima" são inadmissíveis, exigindo-se ações corretivas de curto prazo para o posicionamento ao menos na situação "Regular". O objetivo é permanecer pelo menos na situação "Boa". Para tanto, realizam-se ações preventivas, tanto para se manter nessa situação, quanto para mudar para a situação "Ótima".

\section{A medição do desempenho dos setores pela voz do hóspede}

A medição dos resultados do novo questionário também permite determinar o desempenho dos setores do Hotel Ecológico pela voz do hóspede. Isso é feito agrupando-se as questões dos questionários pertinentes à atuação de cada setor. Como existem questões que abrangem vários setores, algumas delas são chamadas em vários grupos. Quando se conhece a parcela de participação de cada setor em uma dada questão, atribui-se ao mesmo somente a parcela correspondente dos resultados.

As denominações dos níveis de serviço alcançado são as mesmas da Tabela 3, mas a periodicidade de análise não é diária. Os relatórios por setor são fechados mensalmente e por estações (alta, média e baixa) de ocupação do Hotel Ecológico, pois as situações de pico de ocupação

Figura 3: Apresentação dos pontos por questão no novo questionário.

Alta

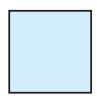

4
Satisfatória

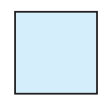

3

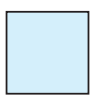

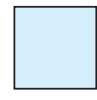

1
Baixa

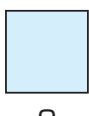

Tabela 3: Classificação da satisfação em função dos resultados dos questionários.

\begin{tabular}{|c|c|}
\hline MÉDIA OBTIDA & SITUAÇÃO \\
\hline Péssima & 0 e menor que 0,5 \\
\hline Ruim & 0,5 e menor que 1,5 \\
\hline Regular & 1,5 e menor que 2,5 \\
\hline Boa & 2,5 e menor que 3,5 \\
\hline Ótima & 3,5 até 4 \\
\hline
\end{tabular}


apresentam impactos na avaliação. Esta diferenciação se fez necessária, pois os resultados obtidos pelo sistema de métricas são comparados com as metas negociadas previamente para o período, que servirão de base para recompensa por desempenho. Como nos períodos de pico utiliza-se muita mão-de-obra temporária e na situação de baixa o quadro de funcionários fica bastante reduzido, os níveis de serviço são aferidos e negociados por estações. Alguns exemplos das metas negociadas são:

- permanecer com a média pelo menos na situação "Boa" durante a alta estação, sem ocorrer pontuação individual 0 (zero). Isso significa que enquanto a média fique na situação "Boa", toleram-se pontuações individuais baixas, porém superiores a 0 (zero);

- não ocorrer pontuação individual 0 (zero) ou 1 (um) durante a baixa estação, ou seja, tolera-se até que a média resulte na situação "Regular", pois a quantidade de funcionários especializados e facilidades é reduzida, quando comparada com as demais estações.

\section{CONSIDERAC̣ÕES SOBRE AS FERRAMENTAS UTILIZADAS}

Com relação à ferramenta Diagrama de Afinidades, a preparação dos cartões de dados exige que no momento de sua utilização para agrupamento seja discutido seu significado, para a adequada compreensão de todos os participantes da dinâmica. Em seguida, é útil questionar os participantes quanto ao entendimento para uniformização do significado, pois em geral cada participante assume inicialmente um significado ligeiramente diferente do outro, o que atrapalha na determinação da afinidade.

A ferramenta Diagrama de Afinidades é de fácil entendimento, pois se trata de ato corriqueiro da vida das pessoas, que naturalmente já agrupam assuntos para serem resolvidos. No entanto, para que os passos sugeridos na Tabela 1 sejam seguidos de maneira sistemática, é necessário que o condutor esteja habituado e exija a sua observância durante o processo.

A assimilação da metodologia do AHP não é tão simples como o Diagrama de Afinidades. Observou-se que as pessoas envolvidas no processo não conseguiram entender o mecanismo da metodologia até que os primeiros julgamentos ocorressem. Observou-se ainda uma certa ansiedade dos participantes durante os intervalos de tempo demandados para a elaboração dos cálculos de prioridade, efetuados automaticamente por um algoritmo que não é bem assimilado pelos participantes. Finalmente, os participantes têm dificuldade de compreender o motivo das inconsistências até que lhes sejam mostradas as sugestões que o software lhes indica, pois estas lhes indicam os motivos da inconsistência. Além disso, apesar das sugestões fornecidas pelo software para a diminuição da inconsistência serem valiosas, algumas vezes o raciocínio lógico dos participantes leva a adotar soluções um pouco diferentes das sugeridas. ercebeu-se que seria também possível monitorar o desempenho setores individualmente, com base na voz dos hóspedes, o que auxiliaria
na gestão dos próprios setores.

De maneira geral, o condutor da aplicação do AHP precisa conhecer bem a ferramenta, que neste caso foi o software Expert Choice, e ser habilidoso, para que durante as pausas de inserção de dados e interpretação dos resultados eles não se distraiam e se percam do objetivo comum. Por outro lado, a possibilidade que o software oferece de julgar tanto utilizando variáveis lingüísticas, quanto por meio numérico, facilita muito a aplicação. Em alguns casos pode-se iniciar o julgamento, por exemplo, com as variáveis lingüísticas e, caso seja difícil, alternar para o meio numérico, ou vice-versa, sem a perda do ritmo da aplicação.

No final, os resultados da metodologia do AHP são validados pelos participantes, pois apesar da dificuldade inicial de entendimento da mesma, os resultados são consistentes com as percepções existentes previamente e as negociações realizadas para a solução das inconsistências são lógicas.

Durante a implementação das ações decorrentes dos resultados do AHP, os responsáveis podem ser levados a querer realizar novos julgamentos, em alguns casos invalidando os julgamentos anteriores. Geralmente, isso pode ocorrer devido ao aumento das informações disponíveis ou a uma mudança ambiental significativa. No caso do Hotel Ecológico não ocorreram mudanças ambientais significativas e foram mantidas as prioridades obtidas durante o processo. No entanto, caso seja necessário considerálas, a metodologia exige que seja reestruturada a árvore hierárquica para contê-las.

\section{CONCLUSÕES}

Neste trabalho foi possível fazer uma análise crítica de um sistema de métricas utilizado em um Hotel Ecológi- 
co, sendo observado que algumas das armadilhas apontadas por Hauser; Katz (1998) estavam presentes no modelo utilizado. As questões críticas eram a não-vinculação a um sistema de recompensas, a falta de prioridade relativa entre as métricas e a falta de alinhamento das métricas aos processos críticos do negócio.

No sistema de obtenção e tratamento da voz do consumidor proposto buscou-se envolver todos os interessados (stakeholders), o que permitiu adequar as métricas aos processos de negócio e às atividades, bem como vinculálas à avaliação dos setores de forma a subsidiar o sistema de recompensas.

Embora existam diversas ferramentas de tomada de decisão que propiciem priorização de critérios, o AHP permitiu sistematizar adequadamente o processo e, de- pois de bem compreendido pelos tomadores de decisão, resultou em uma dinâmica rica que refletiu o consenso do grupo com relação aos critérios.

O uso da ferramenta Diagrama de Afinidades realmente permite reduzir o número de comparações paritárias necessárias durante a aplicação do AHP, acelerando o processo de tomada de decisão, pois a matriz das comparações já de início fica menor do que se fossem comparadas todas as alternativas originais.

Enfim, com a implementação do instrumento de coleta de informações junto ao hóspede, o sistema de tratamento de dados e geração de relatórios e o sistema de recompensas, colocou-se em prática o resultado do processo de tomada de decisão empreendido no Hotel para elaboração do sistema de métricas.

\section{Artigo recebido em 07/02/2003 Aprovado para publicação em 13/09/2003}

\section{- Referências Bibliográficas}

ALBRECHT, K.; BRADFORD, L. J. Serviços com Qualidade - A vantagem competitiva. São Paulo: Makron Books, 1992.

ASSOCIAÇÃO BRASILEIRA DE NORMAS TÉCNICAS. NBR ISO 8402:1994 : Gestão da qualidade e garantia da qualidade - Terminologia. Rio de Janeiro, 1994

BERRY, L.; PARASURAMAN, A. Serviços de marketing: competindo através da qualidade. São Paulo: Maltese-Norma, 1992. 238 p.

CARVALHO, M. M. Qualidade em Projetos. in: AMATO. Manufatura Classe Mundial. São Paulo: Atlas, 2001.

Selecionando Projetos Seis Sigma. in: ROTONDARO. Seis Sigma. São Paulo: Atlas, 2002.

QFD: uma ferramenta de tomada de decisão em projeto. Florianópolis, 1997. Tese (Doutorado em Engenharia de Produção) Departamento de Engenharia Produção e Sistema, Universidade Federal de Santa Catarina. www.eps.ufsc.br/teses $97 / \mathrm{marly} /$ index.html
CHASE, R. B.; GARVIN, D. A. The Service Factory. Harvard Business Review, p. 61-66, jul./aug. 1989.

DYER, J. S. A clarification of "Remarks on the Analytic Hierarchy Process". Management Science, v. 36, n. 3, p. 274-275, 1990b.

Remarks on the Analytic Hierarchy Process. Science Management, v. 36, n. 3, p. 249-258, 1990a.

EXPERT CHOICE. Expert Choice - Trial Version 9.50A05. www.expertchoice.com.

FISHER, C.; SALIBA, M. Managing customer value. Quality Progress, v. 33, n. 6, p. 63-69, 2000.

GARVIN, D. A. Building a Learning Organization. Harvard Business Review, p. 78-91, jul./aug. 1993.

GRÖNROOS, C. Relationship marketing: strategic and tactical implications. Management Decision, v. 34 , n. 3, p. 5-14, 1996.

GUSTAFSSON, A.; JOHNSON, M. Bridging the quality-satisfaction gap. Quality Management Journal, v. 4, n. 3, p. 27-43, 1997.
HAUSER, J.R.; KATZ, G. Metrics: You Are What You Measure!. European Management Journal, v. 16, n. 5, p. 517-528, 1998.

HAUSER,J.R.; CLAUSING, D. The House of Quality. The Harvard Business Review, v. 66, n. 3, p. 63-73, May/June, 1988.

HAMEL; J.R. PRAHALAD, C. K. Corporate imagination and expeditionary marketing. Harvard Business Review, p. 2-11, jul./aug. 1991.

KANO, N., NOBUHIKO, S. FUMIO, T. SHINICHI T. Attractive Quality and Must-Be Quality. [Translated by Glenn Mazur]. Hinshitsu 14, n.2, (February): 39-48, 1984.

LAURINDO, F. J. B.; CARVALHO, M. M.; PESSÔA, M. S. P. SHIMIZU, T. Selecionando uma aplicação de tecnologia da informação com enfoque na eficácia: um estudo de caso de um sistema para PCP. Gestão \& Produção, 2002.

MORITA, H. SHIMIZU, T., LAURINDO, F. J. L. Modelos para estruturar avaliar alternativas de decisão em Tecnologia da Informação. In: XIX ENEGEP - ENCONTRO NACIONAL DE ENGENHARIA DE PRODUÇÃO E V CONGRESSO INTERNACIONAL DE ENGENHARIA INDUSTRIAL, 1999, Rio de Janeiro. Anais. CDROM.
PARASURAMAN et al. Delivering Quality Service. New York: The Free Press, 1990.

PEREIRA, J. C. R. Análise de Dados Qualitativos: Estratégias Metodológicas para as Ciências da Saúde, Humanas e Sociais. 2 ed. São Paulo: Editora da Universidade de São Paulo, 1999. 156 p.

PRAHALAD, C. K.; RAMASWAMY, V. Co-opting customer competence. Harvard Business Review, p. 79-87, jan./ feb. 2000 .

SAATY, T. L. An exposition of the AHP in reply to the paper "Remarks on the Analytic Hierarchy Process". Management Science, v. 36, n. 3, p. 259-268, 1990.

The Analytic Hierarchy Process: Planning, priority, resource allocation. New York: MacGraw-Hill, 1980.

SHIBA, Shoji; GRAHAM, Alan WALDEN, David. TQM: quatro revoluções na gestão da qualidade. Porto Alegre: Artes Médicas, 1997. $409 \mathrm{p}$

YIN, R. K. Case Study Research: Design and Methods. Newbury Park: Sage Publications, 1991. 